\title{
A Dataset for Studying How Human Relates to their Smart Devices
}

\author{
Francesco Lelli \\ Tilburg University, \\ Department of Management
}

\author{
$\underline{\text { Heidi Toivonen }}$ \\ Ghent University \\ Department of Literary Studies
}

\begin{abstract}
In this article, we report how we constructed a dataset that contains the responses to a survey designed for investigating the relationship that humans have with their smart devices. The dataset has been collected in May-July 2020 and is a sample of over 500 respondents of various different ethnicities and backgrounds.

These data have been used for modelling the ways people relate to their devices using the notion of agency. However, the data can be used for complementing any study that intends to investigate a toolmediated communication from the perspective of the users and via a variety of attitudes and expectations the users invest in their devices and in themselves as users.

This article presents the survey items as well as some preliminary data insights. The data have been collected in English and answers have been anonymized in order to ensure GDPR compliance. They are stored in a .csv file containing the respondents' answers to the questions.
\end{abstract}

\section{Keywords}

Agency, $\mathrm{HCl}$, Smart Devices, Human computer interaction, survey

\section{Introduction}

Smart things are becoming more and more an integral part of today's professional and private life [1]. We collected this dataset with the aim of investigating the relationship and interactions people have with their devices as described by the users in a more systematic way, leveraging a number of concepts that have been seen central in the literature describing human-technology interaction, especially the notion of agency [2].

The following specification table gives more information about the dataset in a concise manner.

\begin{tabular}{|l|l|}
\hline Subject & Psychology. Social sciences. Human-Computer Interaction. \\
\hline
\end{tabular}




\begin{tabular}{|c|c|}
\hline Specific subject area & Humans notions of their interactions with their smart devices. \\
\hline Type of data & Microsoft Excel Comma Separated value document(.csv), Table \\
\hline How data were acquired & Questionnaires \\
\hline Data format & Raw \\
\hline $\begin{array}{l}\text { Parameters for data } \\
\text { collection }\end{array}$ & $\begin{array}{l}\text { Background: data has been collected during May-July } 2020 \text { during the } \\
\text { Covid-19 pandemic. } \\
\text { The questionnaire was spread via several channels and was open to } \\
\text { everyone interested in responding to it. Preliminarily information of the } \\
\text { respondents' background factors has been collected for allowing a variety } \\
\text { of analyses needed to categorize the users. }\end{array}$ \\
\hline $\begin{array}{l}\text { Description of data } \\
\text { collection }\end{array}$ & $\begin{array}{l}\text { Data was collected with Qualtrics in an anonymous format and is stored at } \\
\text { the University of Tilburg in complacence with GDPR. The data will be } \\
\text { available for the scientific community for the coming } 10 \text { years in order to } \\
\text { ensure reproducibility of the results as well as to promote future } \\
\text { collaborations. As a part of the survey, the respondents were asked } \\
\text { about their interest in taking part in an interview about their smart } \\
\text { device use. } \\
\text { Data was originally obtained from } 809 \text { participants. After removing all } \\
\text { respondents that did not answer to all questions, the final dataset } \\
\text { included } 587 \text { cases. Because the survey was distributed via the authors' } \\
\text { personal and professional networks, the sample is constituted of highly } \\
\text { educated professionals, many of which can be considered remarkably } \\
\text { familiar with technology. This naturally affects the generalizability of our } \\
\text { results but on the other hand, provides a unique look into the } \\
\text { interactions that a very specific group of users have with their devices. } \\
\text { In the survey, we asked the respondents to choose one smart device and } \\
\text { keep it mind while answering the questions. In case the respondent did } \\
\text { not own any other smart device, they were encouraged to choose their } \\
\text { computer or mobile phone. }\end{array}$ \\
\hline Data source location & Worldwide \\
\hline
\end{tabular}




\begin{tabular}{|l|l|}
\hline Data accessibility & $\begin{array}{l}\text { Repository name: DataverseNL } \\
\text { Data identification number: N.A } \\
\text { Direct URL to data: In process of obtaining one } \\
\text { Instructions for accessing these data: Data are open access } \\
\text { Data are publically available by accessing the following URL: } \\
\text { https://doi.org/10.34894/TRAONY }\end{array}$ \\
\hline $\begin{array}{l}\text { Clarifications, if needed, can be obtained by contacting the corresponding } \\
\text { author of this article as well as the data protection officers. }\end{array}$ \\
\hline $\begin{array}{l}\text { Related research article } \\
\text { Exploratory Study. Preprints 2020, 2020090495 } \\
\text { https://doi.org/10.20944/preprints202009.0495.v2 }\end{array}$ \\
\hline
\end{tabular}

\section{Methods: data collection and initial request to participate}

Invitations to take the survey were collected by contacting participants via using the social networks and social media channels of the authors. What follows is an example of the email invitation used:

Hello,

I am Prof. Francesco Lelli $(*)$ and together with Dr. Heidi Toivonen $(* *)$ we are running a multidisciplinary research on human-smart devices interaction.

We are inviting you to take part in a little survey regarding your relationship with smart devices. In doing this survey, you will be able to reflect on how you relate to technology, while contributing to a study that aims to foster a deeper understanding of human interaction with personal smart devices that are becoming a more and more pervasive element of our everyday life.

We sincerely appreciate your support and collaboration.

Completing the survey will take you no more than 5 minutes. 
Follow this link to the Survey: <link to the survey>

Or copy and paste the URL below into your internet browser: <link to the survey>

You are also welcome to forward this invitation to anybody you think may be interested in participating in this research.

Obviously, you are very welcome to contact us if you have any questions by replying to this email. In addition, if you have done work that you believe is relevant for this research, please get in touch. We look forward to learning from you!

All the Best,

Francesco Lelli and Heidi Toivonen

(*) Doing research on Internet of Things and Information Management, more info at: https://francescolelli.info/

$\left.{ }^{* *}\right)$ Doing research on agency in the field of Psychology, more info at http://www.heiditoivonen.com/

The message was sent only once, without reminders or additional requests to finish uncompleted surveys.

If an individual decided to take part in the survey, he/she had to agree to the following informed consent:

Thanks for your interest in taking this research survey.

We are conducting this study with the aim of improving the relationship that we human beings have with our gadgets.

This survey is anonymous (unless you want to give us your email), but we will collect some information about you in order to segment our population.

For scientific integrity, we securely store this data for at least 10 years and might share the data with other scientific researchers or for other scientific research purposes.

We respect your trust and protect your privacy, and therefore will make sure that the data will not identify you.

Participation in this research study is completely voluntary. You have the right to withdraw at any time or refuse to participate entirely. If you desire to withdraw, please simply close your internet browser. 
You also have the right, in principle, to request access to and rectification, erasure, restriction of or object to the processing of the personal data. More information can be found on the website of Tilburg University: www.tilburguniversity.edu/privacy.

If you have any questions or change your mind, contact us at f.lelli@tilburguniversity.edu

The survey started with a section on the dimensions of user agency and device agency, for which altogether 16 items were designed as follows:

High user agency was measured with:

- Q_1 I'm positive about having this smart device as a part of my daily life;

- Q_5 It is me, the user, who is in control of stopping tasks/processes with my smart device;

- Q_9 I understand how this smart device works;

- Q_13 I am using this smart device to execute task(s) that I have freely chosen.

Low user agency was measured with:

- Q_2 I often feel victimized by my smart device, like it does things to me rather than the other way around;

- Q_6 I am not able to change the way I do things if my smart device is involved; it forces a certain process on me;

- Q_10 I have often had a less than ideal way of using my smart device in the past;

- Q_14 I often think that I cannot really use my smart device to achieve the things I want.

High device agency was measured with:

- Q_3 The smart device runs its actions independently of me/does what it does on its own;

- Q_8 My smart device has intelligence and understanding of its own, independent of me;

- Q_11 My smart device is a true active participant in the interaction I have with it;

- Q_15 Certain things are performed better by my smart device than by me.

Low device agency was measured with:

- Q_4 I feel that my smart device cannot initiate actions on its own;

- Q_7 This smart device cannot independently change the course in how a task is completed; 
- Q_12 My smart device is fundamentally dependent on me, the human user;

- Q_16 My smart device is not really helpful in getting things done.

We also developed scales for other constructs and elements that $\mathrm{HCl}$ and other scholars have considered relevant in characterizing human interaction with (technological) objects. These scales include:

- usability, the pragmatic attributes, or functionality of the device [3], [4],[5],

- cost-effectiveness or price utility, the perceived efficient use of money [6],

- self-extension or identification with the device [4], [7],

- the social aspect of devices, such as social status or social self-image expression [4], [5], [6] and the device's capacity to enhance the user's social relationships [7],

- the emotional aspects of using the device, such as joy or aesthetic pleasure [4], [5], and

- anthropomorphism, attributing human-like qualities to the device [8], [9].

All constructs were measured using multi-item scales designed for the purposes of this study. The survey included also a set of questions for prequalifying and segmenting the population, including items concerning the respondents' gender, age, and educational as well as professional background.

The dataset contains the entire collection of questions as well as all the answers in an anonymous form. The dataset is suitable for statistical analysis and for exploratory research in particular, as authors discussed in [10].

\section{Results}

Data was originally obtained from 809 participants. After removing all respondents that did not answer to all questions, the final dataset included 587 cases. Because the survey was distributed via the authors' personal and professional networks, the sample is constituted of highly educated professionals, many of which are very familiar with technology. This may affect the generalizability of our results but at the same time, provides a unique look into the agency of a very specific group of users. For example, $38.3 \%$ of the respondents are professors. In addition, $53.7 \%$ work in Informatics, Computer Science, or Computer engineering, and $83 \%$ of the respondents say they have professional knowledge of one or more of the following disciplines:

(i) Internet of Things,

(ii) Human Computer Interaction,

(iii) Artificial Intelligence,

(iv) Big Data, or

(v) Requirement Engineering.

Finally, $68.9 \%$ of the respondents were male and $29.9 \%$ female. 
The dataset is released as a single .csv file that can imported in excel as well as in popular data analysis software like SPSS and R. The file is organized as follows:

- Each column represents a question of the survey.

- The first row of each column contains a unique identifier of the question.

- The second row of each column contains the question in the form presented to the participants.

- The answers from the respondents start from the third row.

- $\quad$ The answers are represented in a Likert scale and saved in a numeric value.

The dataset has a supplementary file that contains the entire survey saved as PDF file as example.

\section{Discussion}

The work done in designing the survey and collecting the dataset can be reused in several ways. In particular, its use can be beneficial for the following:

- The dataset provides insight regarding the relationship that humans develop with their smart devices.

- Both researchers and practitioners can understand and refine their understanding on how humans relate with their smart devices.

- The data can be used for further analysis on the topic of human computer interaction as well as for complementing the results of other questionnaires that intend to incorporate the same constructs.

- The data are suitable for various complex statistical analyses. Because a set of qualifier questions have been asked of the respondents (age, gender, education), the data can be segmented to gather insight of users with a particular background.

- The survey items as well as the data itself are of interest for scholars interested in nonhuman agency also outside the field of Human-Computer Interaction.

\section{Conclusions}

In this preprint we introduced the dataset that has been collected for analysing how user's perceive their interactions and relationship with their personal smart devices. The collected data can be used for extending studies that want to incorporate and/or cross correlate the various aspects of this relationship covered by the survey in other topics of investigation.

The Dataset is GDPR compliant and included 587 cases. $53.7 \%$ of the participants work in Informatics, Computer Science, or Computer engineering. In addition, $68.9 \%$ of the respondents were male and $29.9 \%$ female. 


\section{Declaration of Competing Interest}

The authors declare that they have no competing financial interests or personal relationships which have or could be perceived to have influenced the work reported in this article.

\section{References}

[1] Lelli, Francesco. 2019. "Interoperability of the Time of Industry 4.0 and the Internet of Things" Future Internet 11, no. 2: 36. https://doi.org/10.3390/fi11020036

[2] H. Toivonen, "Constructions of agency and nonagency in psychotherapy: The 10 Discursive Tools Model” Ph.D. dissertation, Dept. Psych., University of Jyväskylä., Jyväskylä, Finland, 2019. https://jyx.jyu.fi/handle/123456789/65808

[3] A. Dillon, "Beyond usability: process, outcome and affect in human-computer interactions", Canadian Journal of Library and Information Science vol. 26, no. 4, pp. 57-69, 2002.

[4] M. Hassenzahl, "The Interplay of Beauty, Goodness, and Usability in Interactive Products" HumanComputer Interaction vol. 19, pp. 319-349, 2004.

[5] D-H. Shin, "Cross-analysis of usability and aesthetic in smart devices: what influences users' preferences?" Cross Cultural Management, vol. 19, no. 4, pp. 563-587, 2012. doi:

$10.1108 / 13527601211270020$

[6] H.-W. Kim, S. Gupta, \& J. Koh, "Investigating the intention to purchase digital items in social networking communities: A customer value perspective", Information \& Management, vol. 48, no. 6, pp. 228-234. doi:10.1016/j.im.2011.05.0042011

[7] R.W. Belk, "Possessions and the Extended Self”, Journal of Consumer Research, vol. 15, no. 2, pp. 139-168, 1988.

[8] A. Waytz, J. Heafner, and N. Epley, "The mind in the machine: Anthropomorphism increases trust in an autonomous vehicle", Journal of Experimental Social Psychology vol. 52, pp. 113-117, 2014. doi:10.1016/j.jesp.2014

[9] T.P. Novak and D.L. Hoffman, "Relationship journeys in the internet of things: a new framework for understanding interactions between consumers and smart objects", Journal of the Academy of Marketing Science, vol. 47, pp. 216-237, 2019. doi:10.1007/s11747-018-0608-3

[10] Toivonen, H.; Lelli, F. Agency in Human-Smart Device Relationships: An Exploratory Study. Preprints 2020, 2020090495 https://doi.org/10.20944/preprints202009.0495.v2 